\title{
Assessment of patient-centered outcomes (PROs) in inflammatory bowel disease (IBD): a multicenter survey preceding a cross- disciplinary (functional) consensus
}

Xiaohan Yann ${ }^{1,2}$, Yuqi Qiao ${ }^{1}$, Jinglu Tong ${ }^{1}$, Ren Mao ${ }^{3}$, Jie Liang ${ }^{4}$, Cuicui LV ${ }^{5}$ Yueying Chen ${ }^{6}$, Yiyan Wang ${ }^{7}$, Jun Shen ${ }^{1 *}$ (D) and the Young Investigators for the study of Inflammatory Bowel Diseases (YIIBD)

\begin{abstract}
Background: With a shift in the healthcare paradigm towards a more patient-centered approach, data on inflammatory bowel disease (IBD) needs to be further explored. This study aimed to determine patient perspectives on the effect of IBD and features of patients with lower satisfaction level and compare patient and physician perception of IBD-related Quality of Care (QoC).

Methods: A previously developed pre-standardised set of questions regarding patient-centered outcome (PRO) measures for IBD, comprising 36 items, was administered in five centers, and a concomitant questionnaire for specialised physicians was adapted and administered.

Results: Overall, 1005 patients with IBD met the inclusion criteria. Sixty-five questionnaires were administered to specialised physicians. Both patients and physicians perceived the IBD-related QoC as being satisfactory. Furthermore, this study revealed areas of shortcomings where it comes to patient perceptions. Female sex and the presence of negatively impacting disease characteristics (presence of significant pain or discomfort, lack of energy, feeling fatigued most of the time, experiencing anxiety or depression in the last 2 weeks) were associated with lower satisfaction levels.
\end{abstract}

Conclusions: Our findings can be used in establishing strategies aimed at improving patient QoC and defining strategic priorities. These data can aid in improving the communication of the pressing needs of IBD patients, to both the public payers and health authorities.

Keywords: Patient-centered outcome (PRO), Inflammatory bowel disease (IBD), Quality of care (QoC)

\footnotetext{
*Correspondence: shenjunrj@sina.com

'Division of Gastroenterology and Hepatology, Key Laboratory of

Gastroenterology and Hepatology, Ministry of Health, Inflammatory Bowel Disease Research Center; Renji Hospital, School of Medicine, Shanghai Jiao Tong University; Shanghai Institute of Digestive Disease, 160\# Pu Jian Ave, Shanghai 200127, China

Full list of author information is available at the end of the article
}

(c) The Author(s). 2020 Open Access This article is licensed under a Creative Commons Attribution 4.0 International License, which permits use, sharing, adaptation, distribution and reproduction in any medium or format, as long as you give appropriate credit to the original author(s) and the source, provide a link to the Creative Commons licence, and indicate if changes were made. The images or other third party material in this article are included in the article's Creative Commons licence, unless indicated otherwise in a credit line to the material. If material is not included in the article's Creative Commons licence and your intended use is not permitted by statutory regulation or exceeds the permitted use, you will need to obtain permission directly from the copyright holder. To view a copy of this licence, visit http://creativecommons.org/licenses/by/4.0/. The Creative Commons Public Domain Dedication waiver (http://creativecommons.org/publicdomain/zero/1.0/) applies to the data made available in this article, unless otherwise stated in a credit line to the data. 


\section{Background}

Inflammatory bowel disease (IBD), comprising Crohn's disease (CD), ulcerative colitis (UC) and IBD unclassified (IBD-U), is a chronic immune disease that frequently emerge early in life and requires chronic health care. The wide spectrum of IBD disease severity and frequency of complication occurrence impair patient physical and mental health, quality of life (QoL), and social functioning, resulting in the need for chronic intensive disease monitoring, regular outpatient appointments, hospitalization, and surgery [1]. The prevalence of IBD is increasing globally, with the incidence rising particularly rapidly in Asia [1], accompanied by increasing rates of hospitalization, cumulative surgery, reoperation, and permanent work disability [2,3]. All these lead to high costs to patients and the healthcare system [4]. Quality of care (QoC) is defined as "the degree to which health services for individuals and populations increase the likelihood of desired health outcomes and are consistent with current professional knowledge" [5]; subsequently, the provision of advanced QoC reduces the per capita costs of healthcare [6]. In some studies, QoC was related to both healthcare provider use of technology and interpersonal skills, which depend greatly on the quality of their communication with patients $[7,8]$. The evaluation of QoC consists of the quality of the services provided and patient perception of services received. There is always a gap between physician and patient perception of QoC $[6,9,10]$.

Healthcare is transitioning towards a value-based system $[11,12]$. The acceleration of outcome measurement can unlock the potential of value-based healthcare in driving improvements [13]. Alongside traditional biomedical measures, patient-centered outcome measures are increasingly being used for the evaluation of the management and treatment of different diseases [14-18]. Efforts should be driven towards the application of the patient-centered outcome (PRO) measures in chronic conditions, as the major goals of management are the reversal of disease progression or its arrest, and QoL improvements. Considering the global burden of IBD and its wide-ranging effects on QoL, several attempts have been made aimed at the development of patient-assessed health outcome measures [19]. However, patient-reported outcomes other than those pertaining to disease-related symptoms or QoL are rarely captured in IBD care settings. Therefore, this study was performed with the establishment of the "Standard Set of Patient-centered Outcomes for Inflammatory Bowel Disease - an International, Cross-disciplinary Consensus" as the background survey for the enhancement of actuality basis.

The aims of this study were to assess patient-centered outcomes, including patient perception of QoC, and investigate whether patient-reported outcomes are associated with demographic factors and clinical status.
Subsequently, the differences between patient and physician perception of QoC were also determined.

\section{Methods \\ Participants and methods}

Patients in this multicenter, observational study were enrolled from three hospitals across different provinces of China, covering a population greater than $50,000,000$ people. From March 2016 to November 2017, consecutive inpatients and outpatients with an IBD diagnosis were enrolled.

Inclusion criteria were:

- age at least 18 years;

- verified IBD diagnosis (based on a combination of clinical, laboratory, endoscopic, radiological, and histological findings); and

- ability to understand the questionnaire and provide written informed consent.

\section{Exclusion criteria were:}

- follow-up duration at the center shorter than 12 months at the time of enrolment; or

- inclusion in other clinical trials at baseline.

The questionnaire was delivered either on paper or online to each prospective outpatient while they were waiting for their clinic appointment. Most of the patients submitted a completed questionnaire to the investigators while still in the waiting room. Some patients completed the online version of the survey in the waiting room or shortly thereafter. Inpatients received the questionnaire during their hospital stay. IBD specialists were involved in the entire process of questionnaire admisnistration, and subsequently checked all answers for missing values or inconsistencies. Another concomitant electronic questionnaire for physicians was administered to IBD specialists from multiple hospitals across East China via email.

\section{Questionnaires}

A standard set of patient-centered outcome measures for IBD was previously developed by an international working group $(n=25)$, representing patients, patient associations, gastroenterologists, surgeons, specialist nurses, IBD registries and patient-reported outcome measure methodologists [19]. A systematic review of existing literature, registry data, patient focus groups, a series of teleconferences incorporating a modified Delphi process, and open review periods were used to reach a consensus on a minimum set of standard outcome measures and risk adjustment variables. A prestandardised set was delivered before the final conference.

In this study, we used the simplified Chinese version of a pre-standardised set comprising 36 items. The questionnaire covered four domains: 
- Survival and disease control

- Healthcare utilization

- Disutility of care

- Symptoms, function, and QoL

Except for the descriptive items and two open-ended items, the remaining questions were optional. Sociodemographic variables were self-reported by patients and included data on diagnosis, sex, age, age at diagnosis, education level, work, smoking habits, and surgery history. The questionnaire is presented in Additional Table 1 (Addendum).

Another concomitant electronic questionnaire for physicians was adapted from the patient version, as shown in Additional Table 2 (Addendum).

\section{Data analysis}

To investigate the potential association of patient satisfaction with clinical, epidemiological parameters, and patient-centered outcomes, bivariate correlation analyses (using Pearson's correlation coefficient and Spearman's correlation coefficient) was performed. Independent sample t-tests and one-way analysis of variance, as well as a chi-square test were performed to investigate differences in the clinical, epidemiological parameters, and patient-centered outcomes across the different subgroups. All tests were two-sided with a significance level of $5 \%$, and were performed using $\mathrm{R}$ version 3.3.3.

\section{Results}

\section{Characteristics of enrolled participants}

Overall, 1005 patients with IBD met the inclusion criteria; 925 of them agreed to participate and provided written informed consent. Finally, 891 of the questionnaires (response rate: $88.7 \%$ ) for patients were found to be evaluable. Overall, 522 patients $(58.6 \%)$ had $\mathrm{CD}, 363$ (40.1\%) had UC, and six (0.7\%) had IBD-U. The sociodemographic and clinical data of the responders, by diagnostic group, are shown in Table 1. In addition, 65 questionnaires were administered to IBD specialists, and 55 were considered evaluable. The average duration of physician involvement in IBD care provision was 7

Table 1 Characteristics of patients responded to the survey

\begin{tabular}{|c|c|c|c|c|}
\hline & $C D$ & UC & Total & $P$ value (CD vs. UC) \\
\hline Number of patients, $N(\%)$ & $522(58.6 \%)$ & $363(40.1 \%)$ & 891 & \\
\hline Female sex, $N(\%)$ & $201(38.5 \%)$ & $164(45.2 \%)$ & $362(41 \%)$ & 0.053 \\
\hline Age, years (range) & $37(18-69)$ & $44(18-75)$ & $40(18-75)$ & 0.913 \\
\hline Disease duration since diagnosis, years (range) & $4.1(1-21)$ & $4.5(1-25)$ & $4.2(1-25)$ & 0.214 \\
\hline \multicolumn{5}{|l|}{ Education level, $N(\%)$} \\
\hline Primary & $37(7.1 \%)$ & $38(10.5 \%)$ & $75(8.4 \%)$ & \\
\hline Secondary & $120(23 \%)$ & $92(25.3 \%)$ & $214(24 \%)$ & \\
\hline university & $365(69.9 \%)$ & $233(64.2 \%)$ & $601(67.5 \%)$ & 0.238 \\
\hline \multicolumn{5}{|l|}{ Current occupation, N (\%) } \\
\hline Working (employee) & $281(53.8 \%)$ & $218(60.1 \%)$ & $501(56.2 \%)$ & 0.136 \\
\hline Working (self-employed) & $55(10.5 \%)$ & $52(14.3 \%)$ & $109(12.2 \%)$ & \\
\hline Studying & $45(8.6 \%)$ & $15(4.1 \%)$ & $60(6.7 \%)$ & \\
\hline Unemployed & $36(6.9 \%)$ & $11(3 \%)$ & $47(5.3 \%)$ & \\
\hline Long-term sick leave because of IBD & 69 (13.2\%) & $17(4.7 \%)$ & $86(9.7 \%)$ & \\
\hline Long-term sick leave for other reasons & $1(0.2 \%)$ & $0(0 \%)$ & $1(0.1 \%)$ & \\
\hline Retired early due to IBD & $1(0.2 \%)$ & $4(1.1 \%)$ & $5(0.6 \%)$ & \\
\hline Retired early for other reasons & $13(2.5 \%)$ & $14(3.9 \%)$ & $27(3 \%)$ & \\
\hline Retired (because of age) & $11(2.1 \%)$ & $29(8 \%)$ & $42(4.7 \%)$ & \\
\hline Fulfilling family role as parent or partner & $10(1.9 \%)$ & $3(0.8 \%)$ & $13(1.5 \%)$ & \\
\hline \multicolumn{5}{|l|}{ Smoker, N (\%) } \\
\hline Every day or almost every day & $39(7.5 \%)$ & 39 (10.7\%) & $80(9 \%)$ & \\
\hline At least once per week & $6(1.1 \%)$ & $14(3.9 \%)$ & $20(2.2 \%)$ & \\
\hline At least once per month & $2(0.4 \%)$ & $5(1.4 \%)$ & $7(0.8 \%)$ & \\
\hline Never & 475 (91\%) & 305 (84\%) & $784(88 \%)$ & 0.174 \\
\hline Abdominal surgery history for IBD, $N(\%)$ & 99 (19\%) & $92(25.3 \%)$ & $191(21.4 \%)$ & 0.205 \\
\hline
\end{tabular}


(range: $3-25$ yrs) years. The average percentage of work time involving the provision of care to IBD patients was 12\% (range: 6-21\%).

\section{Patient-reported outcome measures}

In the 2 weeks preceding questionnaire administration, $61.7 \%$ of patients with CD and $41 \%$ of those with UC experienced anxiety or depression due to IBD $(p=0.029)$. Among all the IBD patients with various current occupations, we found that 31 patients with "unemployment" and 58 with "long-term sick leave" shared the highest proportion of feeling anxious or depressed because of his/her IBD. In other words, $86.1 \%$ of the unemployed patients and $84.1 \%$ of the "long-term sick leave" patients felt anxious or depressed, which is much more frequent than those observed in other current occupations, such as "working (employee)" and "working (self-employed)" and "studying", as well as "long-term sick leave for other reasons", "early retirement due to IBD", "early retirement for other reasons", "retirement (because of age)" and "fulfillment of family role as parent or partner". In the
12 months preceding questionnaire administration, the numbers of hospitalizations due to IBD-related symptoms in the CD group and UC group were $1.72(1.8)$ and $0.71(1.6)$, respectively $(p=0.001)$. The proportion of absenteeism from school or college due to IBD-related symptoms in the CD and UC cohorts were 65.6 (108.9) and $28.5(76.4)$ days, respectively $(p=0.002)$. The durations of absence from work in the CD and UC groups were 71.1 (118.2) and 31.7 (84.3) days, respectively ( $p=$ 0.001 ). In the 24 months preceding questionnaire administration, the longest continuous durations of steroid use for IBD in the CD and UC groups was 2.1 (11.8) and 0.5 (4.2) months, respectively $(p=0.001)$. Detailed data on the patient-centered outcomes of the responders, by diagnostic group, are shown in Table 2.

\section{Experience of IBD care}

The average duration from the time medical care was first sought for symptoms that were finally recognized as IBD-related to IBD diagnosis confirmation was 9.8 (19.8) months. The duration to diagnosis significantly differed

Table 2 Patient-centered outcome measures

\begin{tabular}{|c|c|c|c|}
\hline & CD (522) & UC (363) & $P$ value \\
\hline \multicolumn{4}{|l|}{ In the last two weeks, } \\
\hline $\begin{array}{l}\text { IBD has been well controlled } \\
\text { (Yes/ No/ Not sure) }\end{array}$ & 201/133/188 (38.5\%/25.5\%/36\%) & 158/120/85 (43.5\%/33.1\%/23.4\%) & 0.173 \\
\hline $\begin{array}{l}\text { Current treatment is useful in controlling IBD } \\
\text { (Yes/ No/ Not sure/ without any treatment) }\end{array}$ & $211 / 121 / 160 / 30$ (40.4\%/23.2\%/30.7\%/5.7\%) & 118/76/154/15 (32.5\%/20.9\%/42.4\%/4.1\%) & 0.288 \\
\hline $\begin{array}{l}\text { Miss any planned activities because of IBD } \\
\text { (Yes/ No/ Not sure) }\end{array}$ & 203/244/75 (38.9\%/46.7\%/14.4\%) & 141/158/64 (38.8\%/43.5\%/17.6\%) & 0.999 \\
\hline $\begin{array}{l}\text { Wake up at night because of symptoms } \\
\text { of IBD (Yes/ No/ Not sure) }\end{array}$ & 191/233/98 (36.6\%/44.6\%/18.8\%) & 136/190/37 (37.5\%/52.3\%/10.2\%) & 0.997 \\
\hline $\begin{array}{l}\text { Suffer from significant pain or discomfort } \\
\text { (Yes/ No/ Not sure) }\end{array}$ & 223/245/54 (42.7\%/46.9\%/10.3\%) & 176/120/67 (48.5\%/33.1\%/18.5\%) & 0.375 \\
\hline $\begin{array}{l}\text { Feel lacking in energy fatigued for more than } \\
\text { half the time (Yes/ No/ Not sure) }\end{array}$ & $319 / 180 / 23$ (61.1\%/34.5\%/4.4\%) & 212/117/34 (58.4\%/32.2\%/9.4\%) & 0.349 \\
\hline $\begin{array}{l}\text { Feel anxious or depressed because of IBD } \\
\text { (Yes/ No/ Not sure) }\end{array}$ & $322 / 142 / 58(61.7 \% / 27.2 \% / 11.1 \%)$ & 149/130/84 (41\%/35.8\%/23.1\%) & 0.029 \\
\hline $\begin{array}{l}\text { Need a change to treatment } \\
\text { (Yes/ No/ Not sure) }\end{array}$ & 144/173/205 (27.6\%/33.1\%/39.3\%) & 121/108/134 (33.3\%/29.8\%/36.9\%) & 0.083 \\
\hline \multicolumn{4}{|l|}{ In the last 12 months, } \\
\hline Times of flare-ups & $4.9(11.9)$ & $2.3(3.7)$ & 0.064 \\
\hline $\begin{array}{l}\text { Times of hospitalization because of IBD-related } \\
\text { Symptoms }\end{array}$ & $1.72(1.8)$ & $0.71(1.6)$ & 0.001 \\
\hline $\begin{array}{l}\text { absent from school or college due to IBD-related } \\
\text { Symptoms (days) }\end{array}$ & $65.6(108.9)$ & $28.5(76.4)$ & 0.002 \\
\hline $\begin{array}{l}\text { absent from work due to IBD-related symptoms } \\
\text { (days) }\end{array}$ & $71.1(118.2)$ & $31.7(84.3)$ & 0.001 \\
\hline $\begin{array}{l}\text { unable to do normal activities due to IBD-related } \\
\text { Symptoms (days) }\end{array}$ & $32.4(70.5)$ & $14(50)$ & 0.071 \\
\hline $\begin{array}{l}\text { In the last } 24 \text { months, the longest continuous } \\
\text { stretch of time of taking steroid tablets for } \\
\text { IBD (months) }\end{array}$ & $2.1(11.8)$ & $0.5(4.2)$ & 0.001 \\
\hline
\end{tabular}


between the CD and UC groups (13.3 (24.8) vs. 4.5 (5.8) months, $p<0.001$ ), and were positively correlated to age (correlation coefficient $=0.036, p<0.001$ ). There were no significant differences between male and female participants $(p=0.194)$. The average frequency of emergency room presentations for IBD-related symptoms before a definitive diagnosis was reached was 2.6 (5.4) times. The average frequency of emergency room presentation significantly differed between the $\mathrm{CD}$ and $\mathrm{UC}$ groups (3.4 (6.4) vs. 0.99 (1.4) months, $p<0.001)$. There was no significant difference between male and female participants in this regard $(p=0.070)$. In the whole cohort, the frequency of emergency room presentation was positively correlated to time to diagnosis $($ correlation coefficient $=$ 0.215 , confidence interval $[\mathrm{CI}]: 0.023-0.506, p<0.001)$. However, the time to diagnosis was not correlated to age $(p=0.294)$.

In total, 855 patients (96\%) consulted gastroenterologists for IBD, 24 patients (2.7\%) consulted general surgeons, 82 (9.2\%) consulted colorectal surgeons, 13 (1.5\%) consulted other specialists, seven $(0.8 \%)$ consulted specialist nurses, and none of the patients consulted their family doctor. Overall, 615 patients $(69 \%)$ had a regular IBD review appointment regardless of IBD activity status, whereas 276 patients (31\%) did not. There was no significant difference based on sex $(p=0.338)$, education level $(p=0.412)$, and age $(p=0.371)$ in this regard. The average duration of the last IBD consultation was 11.1 (8.3) minutes in the CD group and 12.2 (14.4) minutes in the UC group $(p=0.328)$. There was no significant difference between the sexes $(p=0.172)$ and between patients of different ages $(p=0.379)$. In total, 423 patients $(47.5 \%)$ felt that the consultation time was sufficient for a satisfactory review of the IBD status, whereas 468 patients $(52.5 \%)$ did not feel this to be the case. Eighthundred-and-41 patients (94.4\%) received specialist advice at a hospital or clinic during a flare-up. Few patients received information by telephone (11.2\%) or email (0.6\%). An interesting finding was that 55 patients (29.3\%) felt that the number of toilets was sufficient for patients with IBD during hospitalization, whereas 133 patients $(70.7 \%)$ did not.

\section{Satisfaction with care}

Overall, 295 (56.6\%) patients with CD, 220 (60.6\%) patients with UC, and $46(83.6 \%)$ specialists felt that the level of communication between patients and health specialists was excellent or very good (CD group vs. UC group: $p=0.724$; specialists vs. IBD patients: $p=0.008$ ). A larger number of specialists than patients believed that the level of communication was good; however, there was no difference between patients with $\mathrm{CD}$ and $\mathrm{UC}$ in this regard. A total of 347 (66.4\%) patients with CD, 276 (76\%) patients with UC, and $45(81.8 \%)$ specialists regarded the quality of the IBD care received or provided in the past 12 months as being excellent or very good (CD group vs. UC group: $p=0.898$; specialists vs. IBD patients: $p=0.231$ ). There was no difference between patients with $\mathrm{CD}$ and $\mathrm{UC}$, or between the specialists and patients in this regard. Female patients showed a higher tendency to feel that the quality of communication with specialists $(p=0.037)$ and quality of IBD care $(p=0.019)$ was less satisfactory than male patients. However, patients across different age groups $(p=0.231)$, disease duration groups $(p=0.307)$, education level groups $(P=0.549)$, and history of abdominal surgery for IBD groups $(p=0.113)$ did not show significant differences in terms of the level of satisfaction pertaining to communication with specialists. Similarly, patients across different age groups $(p=0.275)$, disease duration groups $(p=$ $0.292)$, education level groups $(p=0.687)$, and history of abdominal surgery for IBD groups $(p$ value $=0.202)$ did not show significant differences in the quality of IBD care. In the bivariate analyses conducted to further evaluate patient-centered outcomes, patients with significant pain or discomfort were less satisfied with the quality of IBD care than those without $(P=0.043)$. Patients who felt fatigued for the majority of the time were less satisfied with the quality of IBD care than those who did not $(p=0.028)$. Patients who had experienced anxiety or depression in the last 2 weeks were less satisfied with the quality of IBD care than those who had not $(p=0.003)$. There was no statistically significant difference in the perception of IBD management ( $p=0.219)$.

Of all the topics discussed in the consultations, there were significant differences in regarding medical treatment options $(13.4 \%$ of the patients in the $\mathrm{CD}$ group and $30.9 \%$ of those in the UC group felt that this aspect was "not sufficiently discussed," $p<0.001$ ), use of new/ experimental treatments $(38.7 \%$ of the patients in the CD group and $21.5 \%$ of those in the UC group felt this aspect was "sufficiently discussed," whereas 3.1 and $19.6 \%$ of those in the CD and UC groups, respectively, felt it was "not sufficiently discussed," $p<0.001$ ). Detailed data on the patient and specialist perception of satisfaction with healthcare are presented in Table 3.

Using Spearman's correlation, we found that patient level of satisfaction with the quality of IBD care was correlated with the presence of well-coordinated IBD management (correlation coefficient $=0.18$, CI: $0.061-0.703$, $p=0.009$ ) and satisfaction with the level of communication with health specialists (correlation coefficient = 0.457, CI: $0.329-0.692, p<0.001$ ), but was not correlated to adequacy in the number of toilets during time of IBD hospitalisation (correlation coefficient $=0.066$, CI: -0.075 $-0.225, p=0.334$ ).

The topics that the patients with $\mathrm{CD}$ regarded as being insufficiently discussed in the consultations (over 10\%) 


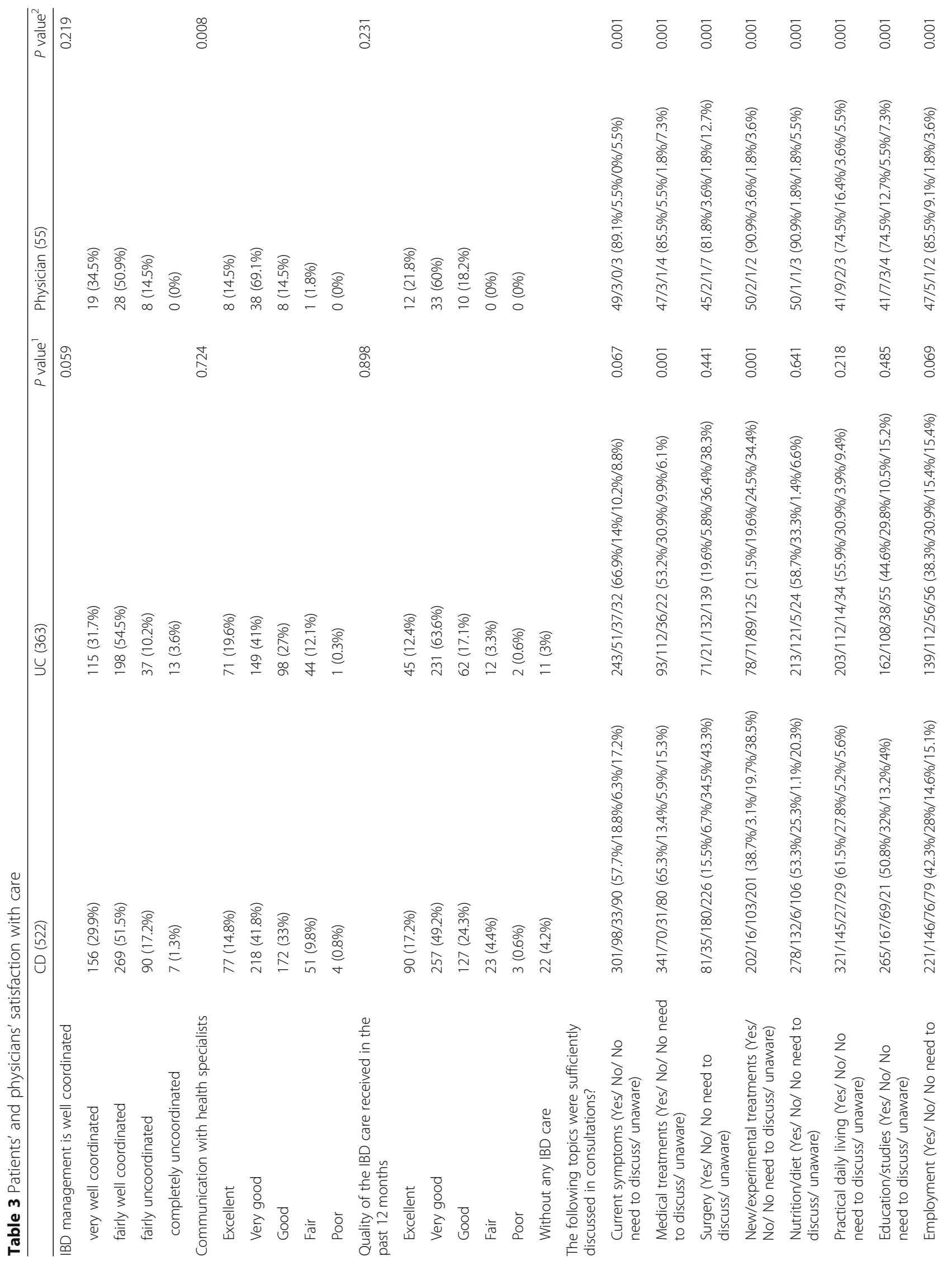




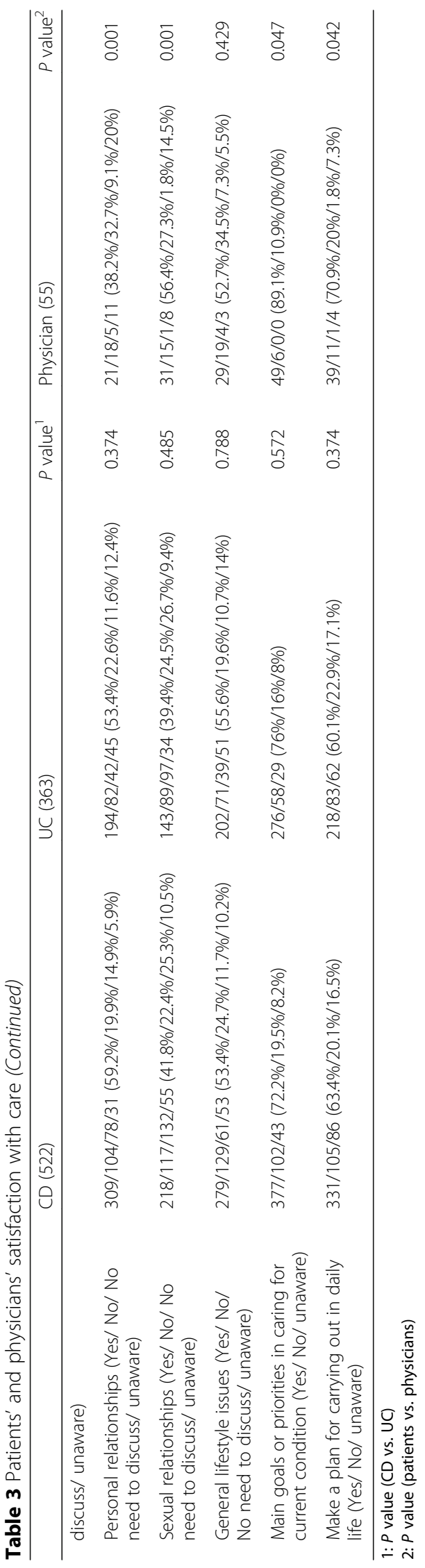


in the order of "highest to lowest" were: education/studies, employment, practical daily living, nutrition/diet, general lifestyle issues, sexual relationships, formulation of a plan for daily life, personal relationships, main goals or priorities in caring for the current condition, current symptoms, and medical treatments. The corresponding topics in the UC group ranked from highest to lowest were: nutrition/diet, employment, practical daily living, medical treatments, education/studies, sexual relationships, formulation of a plan for daily life, personal relationships, general lifestyle issues, new/experimental treatments, main goals or priorities in caring for the current condition, and current symptoms (Table 3 ).

\section{Analysis of the open-ended items}

The two open-ended questions were: "What is the best thing about the care you currently receive?" and "What is the care that you would most like to be changed or improved?" The answers were as follows:

- fewer expenses and better coverage (for drugs such as infliximab) by health insurance;

- provision of more efficient and better-coordinated management, shorter waiting times, and easier access to the purchase of medicines;

- better disease control and fewer hospital visits;

- better level of communication and easy access (such as telephone and Wechat), with a greater degree of information on diets and medicines, as well as disease control (more public lectures and popular science articles);

- demand for the combined use of traditional Chinese medicine with Western medicine;

- better inpatient facilities and a larger number of IBD healthcare providers.

\section{Discussion}

In this study, we found that both patients and physicians perceived the IBD-related QoC as being satisfactory. Furthermore, we uncovered shortcomings according to the patient perception. Female sex and the presence of certain negatively impacting disease characteristics were associated with lower satisfaction levels.

The importance of the systematic tracking and reporting of patient-centered outcomes is gradually being realized. Through the comparison of meaningful patient outcomes, providers can adopt strategies aimed atachieving the best "value" for participating stakeholders; this is defined as value-driven care [19]. The present study was devoted to the pursuit of this aim. When the provision of care is driven by outcomes, remission rates go up [20]. The US Food and Drug Administration (FDA) has advocated the routine inclusion of patient-reported outcomes as co-primary endpoints in clinical trials [21].
Although QoL improvement is a commonly used secondary endpoint in clinical trials, it was the primary endpoint in only one trial focusing on IBD [22] and is rarely captured in routine practice.

In this study, $61.7 \%$ of the patients with CD and $41 \%$ of those with UC experienced anxiety or depression due to IBD in the 2 weeks preceding questionnaire administration. Unemployment and taking long-term sick leave due to IBD ranked the highest in terms of the causes of anxiety and depression, compared to other current occupations. A previous study showed that absence from work and the presence of active disease were the two main factors associated with a reduced health-related QoL (HRQoL) [23]. Another study proved that absence from work, number of physician visits, and the proportion of procedures undergone were related to an impaired HRQoL [24]. Thus, a greater degree of attention should be paid to those with unemployment and longterm sick leave. Previous studies have shown that IBD is associated with a high prevalence of anxiety and depression. Psychological therapies and cognitive behavioral therapy may be beneficial in decreasing the levels of anxiety and depression in IBD [25-27].

None of the patients consulted family doctor. It should be mentioned that there are very few family doctors or general practitioners in China, and that most patients consult specialists.

There has been a tendency for patient perception of the quality of healthcare to be ignored as they are not adequately aware of what constitutes high care quality. As of 2018, no consensus on patient satisfaction or Quality of Care (QoC) measurement had been reached [28]. Previous studies focusing on patient satisfaction with IBD care presented conflicting results in terms of the factors that affect their QoC-related perception [2931]. A judgment of low quality may have resulted as a consequence of extremely high expectations or the provision of a very poor QoC [32]. In addition, it cannot be directly concluded that the conflicting results reflects the diversity of various care centers and geographical location, since this could be explained by methodological differences or bias caused by the selection of participants. In this multicenter study, only $5 \%$ of the patients with $\mathrm{CD}$ and $3.9 \%$ of those with UC, and $0 \%$ of the physicians stated that they were dissatisfied with the quality of IBD care, consistent with previous studies [33]. Therefore, the patients with IBD were satisfied with the QoC provided in the included hospitals. Since each investigated hospital has an IBD care center consisting of an IBD-specialized inpatient and outpatient department and a multidisciplinary team, these measures are inferred to be essential for the improvement of the level of satisfaction with the quality of IBD care. A previous study has shown that even hospitals with a minimal IBD 
service performed better in terms of many process and outcome measures. Hospitals with a partial IBD service showed a greater degree of adherence to the standards for safety monitoring of biologic ( $89 \%$ vs. $59 \%$ ) and immunosuppressive drugs (79\% vs. $55 \%)$, and a rate of admission via an emergency department that was $22 \%$ lower than that in hospitals without such a service [34]. Furthermore, the introduction of an IBD nurse is also essential, which leads to significant cost savings and better QoC, through the reallocation of physician time resources and reductions in the hospitalization rates [35]. As is well-known, the incidence of IBD has increased rapidly in Asia in recent years, especially in countries undergoing rapid industrialization [36, 37]. Our data on the IBD-related QoC may aid local governments in more effectively allocating resources for accelerating the construction of specialized and dedicated IBD care centers [38].

In our study, patient satisfaction with the quality of IBD care was related to the satisfaction with the level of communication with specialists. Patient-physician communication is vital in ensuring patient commitment and involvement in long-term disease self-management [38], and influences complementary and alternative therapies [39]. In medical care, communication is highly associated with better patient adherence to doctor's advice [40]. However, no significant differences were observed between the $\mathrm{CD}$ and UC groups in the level of satisfaction with the quality of IBD care received in the past 12 months. Female patients regarded the quality of IBD care as being worse than male patients. This can be attributed to several factors. A large population-based cohort showed no significant differences in terms of HRQoL between patients with UC and those with CD, overall, whereas a significant reduction in HRQoL was observed in women but not in men compared to the background population [23]. Female patients with IBD show a larger number of intense concerns, a greater level of psychological disturbance, a higher symptom load, and a poorer QoL than men, resulting in reduced satisfaction ratings [41-44]. A lower level of satisfaction amongst female patients was also noted in the QUOTEIBD studies [45, 46]. Moreover, the finding that indicates a lower level of satisfaction amongst women is consistent with those of many other patient satisfaction-related studies $[47,48]$. Secondly, no statistically significant difference was observed between the CD and UC groups in the assessment of the level of communication with health specialists in the past 12 months; however, a greater number of female than male patients assessed the level of communication as being worse. This finding suggests that, in the formulation of an appropriate communication strategy and provision of information about the disease, one should take into account subjective perceptions of QoL and sex-related differences [49]. In terms of the influence of demographic and clinical data on the level of satisfaction with the quality of IBD care in the current study, female patients, patients with significant pain or discomfort, those who felt a lack of energy or were fatigued for the majority of the time, and patients who experienced anxiety or depression in the 2 weeks preceding questionnaire administration were found to be less satisfied with the quality of IBD care than their counterparts. Similarly, a previous study also showed that anxiety-related symptoms were determinants of patient satisfaction among youths/adolescents with IBD [50]. In our study, no major differences related to the patient-perceived QoC was noted when stratification was performed according to disease subtype, age, disease duration, education level or abdominal surgery history. Nonetheless, a previous study showed that older age was associated with modestly higher scores on the Short Inflammatory Bowel Disease Questionnaire and mental HRQoL, but a lower physical HRQoL score [51]. Another study using PROMIS instruments showed that patients with $C D$ had a significantly worse degree of impairment than those with UC in a population of ambulatory adults [49]. However, a prospective study conducted in a high-volume IBD center proved that perceived QoC is associated with sex, disease activity, work productivity and QoL, but not disease phenotype [52].

The bias and difference between specialists and patients requires investigation. Specialists should strive to improve the quality of doctor-patient communication. The differences in the scoring trends between physicians and patients could be related to the generally insufficient communication status due to high inpatient and outpatient department volumes and relative scarcity of healthcare providers, as well as the higher expectations of patients receiving IBD care at centers in first-tier cities. Furthermore, half of the patients considered the consultation time to be insufficient. Moreover, only twothirds of the patients had a regular IBD review appointment regardless of the IBD activity status. Most patients were used to seeking specialist advice during a flare-up at hospitals or clinics; few received advice through telephone or email. The government should allocate a larger volume of funds aimed at improving the doctor-topatient ratio to ensure better communication between physicians and patients.

Furthermore, in this era of growing healthcare cost constraints, providers must also demonstrate a favorable cost:benefit ratio with patient-centered outcome-based intervention; this requires further evaluation beyond the scope of this study. However, making improvements to some of the patient-centered outcomes (for instance, those items related to communication, information, consultation topics, and staff availability) may only result in small or negligible costs. 
This study has some limitations. Firstly, the participants were enrolled from care centers across the eastern parts of mainland China, and may not be representative of the entire Chinese IBD population. The regions included in our study are more developed and industrialized than other parts of China. Secondly, the current study had a cross-sectional observational design. We cannot infer causality from these results, although it was possible to identify measures for improvements in clinical practice and patient care. Last, but not least, this study included a high number of statistical tests, which may result in type I errors. Despite these limitations, the current study provides important insights into the factors associated with patient-centered outcomes, as well as broadens the scope of the discussion pertaining to the status of IBD care in China.

In conclusion, we found that both patients and physicians perceived the IBD-related QoC as being satisfactory. We also identified areas of shortcomings and improvement where it comes to patient perception, and established that female sex and the presence of certain negatively impacting disease characteristics were associated with lower satisfaction levels. Therefore, patient concerns pertaining to their disease must be reassessed regularly, since there are certain aspects of IBD-care that may be improved, as evident from this study.

\section{Supplementary information}

Supplementary information accompanies this paper at https://doi.org/10. 1186/s12955-020-01489-8.

Additional file 1: Table 1. Demographics

Additional file 2: Table 2. Clinician Questionnaire

\section{Abbreviations}

QoC: Quality of care; QoL: Quality of life; IBD: Inflammatory bowel disease; CD: Crohn's disease; HRQoL: Health-related QoL; UC: Ulcerative colitis; IBDU: IBD unclassified; Cl: Confidence interval

\section{Acknowledgments}

We thank all patients who participated in this study.

\section{Authors' contributions}

Xiaohan Yan wrote the paper. Yuqi Qiao, Jinglu Tong, Ren Mao, Jie Liang, Cuicui LV, Yueying Chen and YIIBD did the survey. Yiyan Wang did the statistical analysis. Jun Shen contributed by reviewing other studies and improving the writing of the paper. All authors have read and approved the final manuscript.

\section{Funding}

This work was supported by grants from the National Natural Science Foundation of China (No. 81770545), MDT Project of Clinical Research Innovation Foundation, Renji Hospital, School of Medicine, Shanghai Jiaotong University (PYl-17-003) and Top-Level Clinical Discipline Project of Shanghai Pudong (PWYgf 2018-04).

\section{Availability of data and materials}

The datasets collected and/or analyzed during the current study are available from the corresponding author upon reasonable request.

\section{Competing interest}

The authors have declared no conflicts of interest.

Ethics approval and consent to participate

All participants enrolled in this study provided written informed consent. The study protocol was approved by the Research Ethics Committee of Renji Hospital (School of Medicine, Shanghai Jiao Tong University, Shanghai, China). All procedures performed in studies involving human participants were in accordance with the ethical standards of the Research Ethics Committee of Renji Hospital (School of Medicine, Shanghai Jiao Tong University, Shanghai, China) and with the 1964 Helsinki declaration and its later amendments or comparable ethical standards.

\section{Consent for publication}

Not applicable.

\section{Author details}

${ }^{1}$ Division of Gastroenterology and Hepatology, Key Laboratory of Gastroenterology and Hepatology, Ministry of Health, Inflammatory Bowel Disease Research Center; Renji Hospital, School of Medicine, Shanghai Jiao Tong University; Shanghai Institute of Digestive Disease, 160\# Pu Jian Ave, Shanghai 200127, China. Endoscopy Center, Shanghai East Hospital, Tongji University School of Medicine, Shanghai 200120, China. ${ }^{3}$ Department of Gastroenterology, the First Affiliated Hospital, Sun Yat-sen University, No.58, Zhong Shan Er Lu, Guangzhou 510080, China. ${ }^{4}$ Department of Gastroenterology, Xijing Hospital, Air Force Medical University, Chang Le Xi Lu, Xi'an 710032, China. ${ }^{5}$ Department of Gastroenterology, the Third Hospital, Liao Cheng, China. ${ }^{6}$ Department of Gastroenterology, Zhong Shan Hospital, the Xiamen University, Xiamen, China. ${ }^{7}$ Department of statistics, University of Leeds, Leeds, England.

Received: 31 August 2019 Accepted: 10 July 2020

Published online: 20 July 2020

References

1. Ng SC, Tang W, Ching JY, Wong M, Chow CM, Hui AJ, Wong TC, Leung VK, Tsang SW, Yu HH, et al. Incidence and phenotype of inflammatory bowel disease based on results from the Asia-pacific Crohn's and colitis epidemiology study. Gastroenterology. 2013;145(1):158-65 e152.

2. Burisch J, Jess T, Martinato M, Lakatos PL. The burden of inflammatory bowel disease in Europe. J Crohns Colitis. 2013;7(4):322-37.

3. Kaplan GG. The global burden of IBD: from 2015 to 2025. Nat Rev Gastroenterol Hepatol. 2015:12(12):720-7.

4. Kappelman MD, Moore KR, Allen JK, Cook SF. Recent trends in the prevalence of Crohn's disease and ulcerative colitis in a commercially insured US population. Dig Dis Sci. 2013;58(2):519.

5. Chassin MR, Galvin RW. The urgent need to improve health care quality: Institute of Medicine National Roundtable on health care quality. JAMA. 1998;280(11):1000-5.

6. Spiegel M, Pechlaner C. Quality of health care delivered to adults in the United States. N Engl J Med. 2003;348(349):2635-45.

7. Listed N. The quality of care: how can it be assessed? JAMA. 1989;261(8): 1151

8. Donabedian A. Evaluating the quality of medical care. 1966. Milbank Q. 2005;83(4):691-729.

9. Kappelman MD, Palmer L, Boyle BM, Rubin DT. Quality of care in inflammatory bowel disease: a review and discussion. Inflamm Bowel Dis. 2010:16(1):125-33.

10. GY SCAM, Ullman TA. Improving quality of care in IBD: a STEEEP challenge. Inflamm Bowel Dis. 2010;16(1):134-6.

11. Porter ME. A strategy for health care reform--toward a value-based system. N Engl J Med. 2009;361(2):109-12.

12. Larsson S, Lawyer P, Garellick G, Lindahl B, Lundström M. Use of 13 disease registries in 5 countries demonstrates the potential to use outcome data to improve health care's value. Health Aff. 2012;31(1):220-7.

13. Porter ME, Larsson S, Lee TH. Standardizing patient outcomes measurement N Engl J Med. 2016;374(6):504.

14. Mak KS, Bommel ACMV, Stowell C, Abrahm JL, Baker M, Baldotto CS, Baldwin DR, Borthwick D, Carbone DP, Chen AB. Defining a standard set of patient-centred outcomes for lung cancer. Eur Respir J. 2016;48(3):852-60. 
15. Mcnamara RL, Spatz ES, Kelley TA, Stowell CJ, Beltrame J, Heidenreich P, Tresserras R, Jernberg T, Chua T, Morgan L. Standardized Outcome Measurement for Patients With Coronary Artery Disease: Consensus From the International Consortium for Health Outcomes Measurement (ICHOM). J Am Heart Assoc. 2015;4(5)

16. Ong WL, Schouwenburg MG, Acm VB, Stowell C, Allison KH, Benn KE, Browne JP, Cooter RD, Delaney GP, Duhoux FP. A standard set of valuebased patient-centered outcomes for breast Cancer: the international consortium for health outcomes measurement (ICHOM) initiative. JAMA Oncol. 2017;3(5):677-85.

17. Zerillo JA, Schouwenburg MG, van Bommel AC, Stowell C, Lippa J, Bauer D, Berger AM, Boland G, Borras JM, Buss MK. An international collaborative standardizing a comprehensive patient-centered outcomes measurement set for colorectal Cancer. JAMA Oncol. 2017;3(5):686.

18. De Roos P, Bloem BR, Kelley TA, Antonini A, Dodel R, Hagell P, Marras C, Martinezmartin P, Mehta SH, Odin P. A consensus set of outcomes for Parkinson's disease from the international consortium for health outcomes measurement. J Parkinsons Dis. 2017;7(3):533-43.

19. Kim AH, Roberts C, Feagan BG, Banerjee R, Bemelman W, Bodger K, Derieppe M, Dignass A, Driscoll R, Fitzpatrick $R$, et al. Developing a standard set of patient-centred outcomes for inflammatory bowel disease-an international, cross-disciplinary consensus. J Crohn's Colitis. 2018;12(4):408-18.

20. Crandall WV, Margolis PA, Kappelman MD, King EC, Pratt JM, Boyle BM, Duffy LF, Grunow JE, Kim SC, Leibowitz I. Improved outcomes in a quality improvement collaborative for pediatric inflammatory bowel disease. Pediatrics. 2012;129(4):e1030.

21. Bradley C, Psychol C. Patient-reported outcome measures: use in medical product development to support labeling claims FDA draft guidance or industry 2006. Health Qual Life Outcomes. 2006;4.

22. Williams JG, Alam MF, Alrubaiy L, Arnott I, Clement C, Cohen D, Gordon JN, Hawthorne AB, Hilton M, Hutchings HA. Infliximab versus ciclosporin for steroid-resistant acute severe ulcerative colitis (CONSTRUCT): a mixed methods, open-label, pragmatic randomised trial. Lancet Gastroenterol Hepatol. 2016;1(1):15-24.

23. Huppertz-Hauss G, Lie HM, Jelsness-Jørgensen LP, Henriksen M, Høie O, Jahnsen J, Hoff G, Moum B, Bernklev T. Health-related quality of life in patients with inflammatory bowel disease 20 years after diagnosis: results from the IBSEN study. Inflamm Bowel Dis. 2016;22(7):1679.

24. Nurmi E, Haapamãki J, Paavilainen E, Rantanen A, Hillilã M, Arkkila P. The burden of inflammatory bowel disease on health care utilization and quality of life. Scand J Gastroenterol. 2013;48(1):51-7.

25. Prisco V, lannaccone T. Inflammatory bowel disease and quality of life: psychopathological variants. Recenti Prog Med. 2017;108(2):83-9.

26. Bennebroek Evertsz F, Sprangers MAG, Sitnikova K, Stokkers PCF, Ponsioen CY, Bartelsman J, van Bodegraven AA, Fischer S, Depla A, Mallant RC, et al. Effectiveness of cognitive-behavioral therapy on quality of life, anxiety, and depressive symptoms among patients with inflammatory bowel disease: a multicenter randomized controlled trial. J Consult Clin Psychol. 2017:85(9):918-25.

27. Gracie DJ, Irvine AJ, Sood R, Mikocka-Walus A, Hamlin PJ, Ford AC. Effect of psychological therapy on disease activity, psychological comorbidity, and quality of life in inflammatory bowel disease: a systematic review and metaanalysis. Lancet Gastroenterol Hepatol. 2017;2(3):189-99.

28. dEI V, Stockbrügger R, Russel M. Influence of quality of care on quality of life in inflammatory bowel disease (IBD): literature review and studies planned. Eur J Internal Med. 2000;11(4):228

29. Lönnfors S, Vermeire S, Greco M, Hommes D, Bell C, Avedano L. IBD and health-related quality of life -- discovering the true impact. J Crohns Colitis. 2014;8(10):1281-6.

30. Soares JB, Marinho AS, Fernandes D, Moreira GB, Camila-Dias C, Gonçalves $R$, Magro F. Assessing overall patient satisfaction in inflammatory bowel disease using structural equation modeling. Eur J Gastroenterol Hepatol. 2015;27(8).

31. Casellas F, Vera I, Ginard D, Torrejón A. Inflammatory bowel disease patient's satisfaction with healthcare services received. Physicians' and nurses' perceptions. Rev Esp Enferm Dig. 2013;105(7):385.

32. Van Campen C, Sixma H, Friele RD, Kerssens JJ, Peters L. Quality of care and patient satisfaction: a review of measuring instruments. Med Care Res Rev Mcrr. 1995;52(1):109.
33. Jelsness-Jørgensen LP, Bernklev T, Hovde $\varnothing$, Prytz BI, Huppertz-Hauss G, Moum B, Lie HM. Patients' perceptions of quality of care and follow-up in inflammatory bowel disease. Scand J Gastroenterol. 2015;51(4):434.

34. Massuger W, Moore GTC, Andrews JM, Kilkenny MF, Reyneke M, Knowles S, Purcell L, Alex G, Buckton S, Page AT, et al. Crohn's \& Colitis Australia inflammatory bowel disease audit: measuring the quality of care in Australia. Int Med J. 2019;49(7):859-66.

35. Molander P, Jussila A, Toivonen T, Makkeli P, Alho A, Kolho KL. The impacts of an inflammatory bowel disease nurse specialist on the quality of care and costs in Finland. Scand J Gastroenterol. 2018;53(12):1463-8.

36. Lee D, Albenberg L, Compher C, Baldassano R, Piccoli D, Lewis JD, Wu GD. Diet in the pathogenesis and treatment of inflammatory bowel diseases. Gastroenterology. 2015;148(6):1087-106.

37. Kaplan GG, Ng SC. Understanding and Preventing the Global Increase of Inflammatory Bowel Disease. Gastroenterology. 152(2):313-21 e312.

38. Panés J, O'Connor M, Peyrinbiroulet L, Irving P, Petersson J, Colombel JF. Improving quality of care in inflammatory bowel disease: what changes can be made today? J Crohns Colitis. 2014;8(9):919-26.

39. Réme M, Andrews JM, Antonina MW, Peter B. Doctor communication quality and Friends' attitudes influence complementary medicine use in inflammatory bowel disease. World J Gastroenterol. 2015;21(12):3663-70

40. Zolnierek KBH, Dimatteo MR. Physician communication and patient adherence to treatment: a meta-analysis. Med Care. 2009;47(8):826-34.

41. Muller KR, Prosser R, Bampton P, Mountifield R, Andrews JM. Female gender and surgery impair relationships, body image, and sexuality in inflammatory bowel disease: patient perceptions. Inflamm Bowel Dis. 2010;16(4):657-63.

42. Lesuis N, Befrits R, Nyberg F, Vollenhoven RFV. Gender and the treatment of immune-mediated chronic inflammatory diseases: rheumatoid arthritis, inflammatory bowel disease and psoriasis: an observational study. BMC Med,10,1(2012-08-01). 2012; 10(1):82.

43. Mussell M, Böcker U, Nagel N, Singer MV. Predictors of disease-related concerns and other aspects of health-related quality of life in outpatients with inflammatory bowel disease. Eur J Gastroenterol Hepatol. 2004;16(12):1273.

44. Hauser G, Tkalcić M, Stimac D, Milić S, Sincić BM. Gender related differences in quality of life and affective status in patients with inflammatory bowel disease. Coll Antropol. 2011; 35 Suppl 2(1):203

45. van der Eijk I, Sixma H, Smeets T, Veloso FT, Odes S, Montague S, Fornaciari G, Moum B, Stockbrügger R, Russel M, et al. Quality of health care in inflammatory bowel disease: development of a reliable questionnaire (QUOTE-IBD) and first results. Am J Gastroenterol. 2001;96(12):3329-36.

46. Vasudevan A, Arachchi A, van Langenberg DR. Assessing patient satisfaction in inflammatory bowel disease using the QUOTE-IBD survey: a small step for clinicians, a potentially large step for improving quality of care. J Crohns Colitis. 2013;7(9):e367-74.

47. Woods SE, Heidari Z. The influence of gender on patient satisfaction. J Gender-Specific Med. 2003;6(4):30.

48. Weisman CS, Rich DE, Rogers J, Crawford KG, Grayson CE, Henderson JT. Gender and patient satisfaction with primary care: tuning in to women in quality measurement. J Women's Health Gender-Based Med. 2000;9(6):657.

49. Pittet V, Vaucher C, Froehlich F, Burnand B, Michetti P, Maillard MH. Patient self-reported concerns in inflammatory bowel diseases: a gender-specific subjective quality-of-life indicator. PLoS One. 2017;12(2):e0171864.

50. Timmer A, de Sordi D, Menke E, Peplies J, Classen M, Koletzko S, OttoSobotka F. Modeling determinants of satisfaction with health care in youth with inflammatory bowel disease: a cross-sectional survey. Clin Epidemiol. 2018;10:1289-305

51. Velonias G, Conway G, Andrews E, Garber JJ, Khalili H, Yajnik V, Ananthakrishnan AN. Older age- and health-related quality of life in inflammatory bowel diseases. Inflamm Bowel Dis. 2017;23(2):283-8.

52. Gonczi L, Kurti Z, Verdon C, Reinglas J, Kohen R, Morin I, Chavez K, Bessissow T, Afif W, Wild G, et al. Perceived quality of care is associated to disease activity, quality of life, work productivity and gender but not disease phenotype: a prospective study in a high-volume IBD center. J Crohn's Colitis. 2019.

\section{Publisher's Note}

Springer Nature remains neutral with regard to jurisdictional claims in published maps and institutional affiliations. 